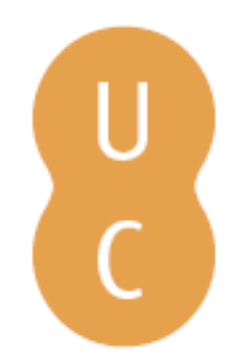

\title{
nommalina
}

Thomé Rodrigues Sobral e a análise química na Universidade de Coimbra no início do século XIX
Autor(es):
Amorim-Costa, António Marinho
Publicado por: Imprensa da Universidade de Coimbra
URL
persistente:
URI:http://hdl.handle.net/10316.2/38449
DOI:
DOI:http://dx.doi.org/10.14195/978-989-26-0764-1_13
Accessed : $\quad$ 26-Apr-2023 14:41:31

A navegação consulta e descarregamento dos títulos inseridos nas Bibliotecas Digitais UC Digitalis, UC Pombalina e UC Impactum, pressupõem a aceitação plena e sem reservas dos Termos e Condições de Uso destas Bibliotecas Digitais, disponíveis em https://digitalis.uc.pt/pt-pt/termos.

Conforme exposto nos referidos Termos e Condições de Uso, o descarregamento de títulos de acesso restrito requer uma licença válida de autorização devendo o utilizador aceder ao(s) documento(s) a partir de um endereço de IP da instituição detentora da supramencionada licença.

Ao utilizador é apenas permitido o descarregamento para uso pessoal, pelo que o emprego do(s) título(s) descarregado(s) para outro fim, designadamente comercial, carece de autorização do respetivo autor ou editor da obra.

Na medida em que todas as obras da UC Digitalis se encontram protegidas pelo Código do Direito de Autor e Direitos Conexos e demais legislação aplicável, toda a cópia, parcial ou total, deste documento, nos casos em que é legalmente admitida, deverá conter ou fazer-se acompanhar por este aviso.

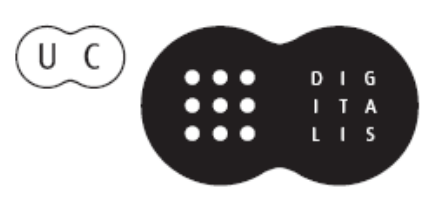


Departamento de Química, Faculdade de Ciências e Tecnologia da Universidade de Coimbra acosta@ci.uc.pt

\section{Thomé Rodrigues Sobral e a Análise Química na Universidade De Coimbra No ÍNICIO DO SÉCULO XIX}

\section{António Marinho Amorim-Costa}

Thomé Rodrigues Sobral, filho de João Rodrigues e Isabel Pires, nasceu em Felgueiras, Moncorvo, a 21 de Dezembro de 1759. Matriculou-se na Universidade de Coimbra, em Matemática e Filosofia, a 29 de Outubro de 1779. Foi ordenado presbítero na Arquidiocese de Braga em 1782, e concluiu o curso na Faculdade de Matemática e Filosofia em 26 de Junho de 1783.

Contratado como docente da Faculdade de Filosofia da Universidade de Coimbra, em Julho de 1786, foi provido no cargo de Demonstrador de História Natural, e depois, substituto extraordinário para as cadeiras de Física (em Outubro de 1786 e Julho de 1788), História Natural (em Julho de 1787) e Química (em Julho de 1789). Por carta régia de 24 de Janeiro de 1791, com a jubilação de Domingos Vandelli (1735-1816), foi nomeado Director do Laboratório Chimico, sucedendo-lhe no cargo que ele exercia desde 1772, por convite expresso do Marquês de Pombal. Pela mesma carta régia, foi nomeado Lente de Prima, proprietário da cadeira de Química e Metalurgia.

Foi sócio da Academia das Ciências de Lisboa, Cavaleiro professo da Ordem de Cristo e deputado às Cortes Constituintes de 1821. Em 24 de Maio de 1828 foi nomeado vice-reitor da Universidade de Coimbra, não tendo chegado a aceitar o cargo por doença, morrendo um ano depois, em Setembro de 1829.

Referindo-se à acção que Rodrigues Sobral desenvolveu como Director do Laboratório Químico da Universidade de Coimbra, o cronista da Faculdade de Filosofia da mesma Universidade, na celebração do primeiro centenário da Reforma Pombalina, o Professor Joaquim Augusto Simões de Carvalho, resume:

"No tempo da direcção deste Professor, os trabalhos práticos do Laboratório não cessavam, não só em delicadas investigações de chymica, mas ainda nas mais importantes applicações industriaes. Faziam-se várias e repetidas experiências concernentes à respiração das plantas e a outros phenomenos da physiologia vegetal; ensaiavam-se processos para a conservação das substancias animaes e vegetaes; preparavam-se sem descanso os principaes productos chimicos. Os Professores da Faculdade de Philosofia e os de Medicina frequentavam muito o laboratório; auxiliavam o seu director nas mais arriscadas experiencias de chimica; e emprehendiam outros trabalhos relativos às sciencias que ensinavam, consultando sempre e ouvindo os sábios conselhos do seu illustre collega. Foi uma épocha florescente e memoravel do ensino da chimica em Portugal" (CARVALHO, 1872, p. 282). 
Pelos muito trabalho que fez ao serviço da Química, trabalho esse que deixou extensa e minuciosamente relatado em longos escritos, e também pelas teorias que desenvolveu para o explicar, Tomé Rodrigues Sobral foi reconhecido por vários de seus discípulos e sucessores, como "o Mestre da pólvora”, “o Lavoisier Português" e "o Chaptal Português”. Referindo aqui muito do que ele fez no domínio da análise química, reconheceremos facilmente a razão de ser de qualquer destes epítetos (AMORIM-COSTA 1984, pp. 67-95)

\section{Rodrigues Sobral, o “Mestre da Pólvora”}

Na sua Nota sobre os Trabalhos em grande que no Laboratório Quimico da Universidade poderão Praticar-se..., numa observação sobre os usos importantes e extensos do salitre, Rodrigues Sobral descreve a situação que se viveu no Laboratório Químico da Universidade, quando, em 1808, os exércitos de Napoleão, conduzidos por Junot, atacaram Coimbra. Citamos:

“...No dia memorável 23 de Junho de 1808, dia da abençoada, posto que arriscada, revolução contra os Francezes, que se-havião ja apoderado de grande parte das nossas praças, e por consequencia das nossas polvoras e armamentos, gritava-se por toda a parte ás armas; o valor e o patriotismo iam até o enthusiasmo: mas a falta de polvora era quase absoluta. Eu me-vi inopinadamente encarregado pelas Authoridades-constituidas de a-fabricar, posso dizer sem meios, de um dia ate o outro, se-fosse possivel: e ate posso accrescentar, quasi me-achei sacrificado á impostura (por não dizer á perfidia) de quem quiz persuadir que no Laboratorio da Universidade, onde por via de regra so se-fabricam algumas libras para o ensino, se-podiam diariamente fabricar arrobas: como pois tirar-me de tão apertada situação, e desempenhar tão dificil, e ao mesmo tempo tão importante commissão que ao depois me-veio a ser tão fatal?

Entao foi que eu vi com mágoa os funestos effeitos da falta de uma boa nitreira, que ja então nos-teria fornecido abundantes colheitas de salitre, cuja falta n'aquella occasião nos-era tao sensivel, se a proposta que eu tinha feito alguns annos antes sobre o estabelecimento de uma nitreira houvesse sido attendida: proposta que ainda hoje repito; e oxalá que com maior sucesso! Todas as lojas de droguistas, e todas as boticas de Coimbra, fóram immediatamente esgotadas das pequenas quantidades de salitre que nellas se achou: mas todo era nada para a nossa necessidade. Despediram-se portanto homens capazes para as Cidades de Aveiro, Porto e Braga com as ordens necessarias para comprar todo o salitre que se-achasse. Tal foi o nosso único recurso para se-fabricar dentro em pouco tempo uma quantidade de pólvora (dos diários dos trabalhos do Laboratório consta que já pelos princípios de Agosto seguinte se-haviam fabricado de pólvora perto de 100 arrobas) a qual se não bastou à nossa necessidade e à defesa de Coimbra, influio pelo menos muito n'ella, animando-se muito o Povo e a mesma Tropa, em quanto não chegaram os abundantes soccorros dos nossos Alliados e Protectores" (SOBRAL 1816B, pp.304-305).

\section{Referindo-se à mesma situação, escreveu o director do Jornal de Coimbra:}

"A experiência pública e authenticada por attestados de Artilheiros que se-achavam em Coimbra, que se fez sobre a ponte do Mondego, decidio sem equivoco da superioridade e valentia da polvora, que alias com tanta precipitação se fabricava e apenas mal se-enxugava na estufa do 
Laboratorio. O mesmo Lente (o Professor Rodrigues Sobral) não só dirigio, mas preparou por suas mãos outras munições de guerra: espoletas tanto de peça como de granada; estopins; velas de mixto; murrao, etc. Artigos todos de primeira necessidade e que faltavam em Coimbra, em quanto não chegáram os poderosos e abundantes soccorros que a Nação Ingleza se-apressou a mandar para Coimbra, a cuja chegada sendo tudo remettido ao Laboratorio e alli depositado para sua distribuição, que foi sempre feita pelo dito Professor segundo as requisições que se faziam pelos Chefes da Força armada, o dito Professor teve a satisfaçao de ouvir da boca de diversos Officiaes Inglezes os mais lisongeiros elogios" (CASTILHO, 1814, p.285).

Ainda sobre a mesma situação, escreveu Jose Accursio das Neves, salientando a acção de outros Professores que no Laboratório Químico colaboraram na dita preparação da pólvora necessária e outro material de necessidade urgente para fazer face ao exército francês:

"No dia 26 pelas dez horas da noite appareceu com grandes applausos fabricada a primeira porção de polvora; e neste trabalho se continuou noite e dia debaixo da inspecção do dr. Thome Rodrigues Sobral, lente de chimica. Não se sabiam fazer cartuxos, nem havia balas; mas a essa mesma hora se mandaram buscar dois soldados portuguezes convalescentes, que estavam no hospital, para se empregarem no cartuxame, e officiaes de ourives e funileiros para fundirem balas. lgualmente foram chamados um sargento e alguns soldados, que estavam destacados na ferraria de Thomar, debaixo das ordens do lente de metallurgia e intendente das minas, o dr. Jose Bonifacio de Andrada e Silva, para trabalharem no cartuxame; e principiou a fazer-se metralha para quando houvesse peças, que já se esperavam da Figueira. $0 \mathrm{dr}$. Joaquim Baptista foi um dos que mais se distinguiram nestes trabalhos, desenvolvendo, com grande utilidade, os seus muitos conhecimentos theoricos e practicos. 0 dr. Jose Bonifacio de Andrada, que ao estudo e practica das sciencias naturaes e das artes ajunta o da jurisprudencia, e um grande conhecimento do mundo, adquirido pela lição e pelas viagens, ficou trabalhando juncto à pessoa do governador; e por isso teve menos parte naquelles objectos. 0s lentes e doutores das outras faculdades tambem empregaram ultimamente as suas forças e talentos: o berço das letras tornou-se um arsenal de guerra” (Neves, 1820, citado in Carvalho, 1872, pp.182-183).

Informado de todos estes trabalhos e serviços feitos no Laboratório Chimico sob a direcção de Rodrigues-Sobral, o Exército de Massena quando chegou a Coimbra perguntou com empenho pela casa do Mestre da pólvora. A casa foi reduzida a cinzas pelo fogo que o exército lhe pegou; o epíteto perdurou para a história (CASTILHO, 1814, p.286).

Fruto do flagelo da guerra contra os franceses em que a notória actividade química desenvolvida por Rodrigues Sobral lhe mereceu o epíteto de "mestre da pólvora", grassou em todas as freguesias de Coimbra e em muitos outros pontos do País, em Agosto de 1809, uma epidemia em que a peste devastava as populações a ritmo quase incontornável. Tornaram-se então notáveis as operações levadas a cabo, sob sua orientação, para atalhar o progresso do contágio. Por elas vemos quanto ele estava familiarizado com os diversos processos químicos necessários para o fazer, fosse quanto aos materiais a usar, fosse quanto ao modo de os preparar. O relato diário dessas operaçóes, publicado primeiramente no periódico de Coimbra Minerva Lusitana e, depois, num longo escrito no Jornal de Coimbra, não deixa dúvida. Servindo-nos do texto publicado no Jornal de Coimbra limitar-nos-emos a citar: 
"Para o efeito se fizeram fabricar no Laboratório pequenos vazos de barro muito commodos e em 17 de Agosto de 1809 se deram em Coimbra as primeiras providencias, depois das quaes se procedeo às fumigações com o gaz muriatico oxigenado em todos aquelles lugares, edificios publicos, hospitaes, quarteis de tropa de que se achava então Coimbra chêa, cadêas, e outros pontos, onde as provas de contagio pareciam menos equivocas, ou se queria mesmo prevenir a sua fatal propagação: dous annos depois se dão as mesmas ou semelhantes providencias na Capital por motivos semelhantes (...) o precioso meio anti-contagioso que vou novamente recommendar ao Publico, torna o cel. Guiton digno do reconhecimento geral de todos os que têm e desejam conservallo na presença ainda do contagio mais furioso (...); não se pense que eu sou menos exacto quando deixo subsistir para o Sabio chimico de Dijon toda a gloria d'esta Descoberta. Eu sei bem que este Sábio chimico, para desinfectar a Cathedral de Dijon em 6 de Março de 1773, não empregou o gaz muriatico oxigenado, mas sim o gaz muriatico ordinário" (SOBRAL 1813, pp. 108-110).

\section{Referindo a preparação deste gaz muriático escreve mais adiante:}

"Elle não existe na natureza, mas he meramente producto da arte: a sua primeira existência deve-se ao cel. Scheel; mas o completo conhecimento da sua natureza e composição he o resultado dos trabalhos posteriores ao mesmo Chimico. 0s seus elementos ou principios são, de huma parte e como fazendo a sua base, o acido muriatico, ou do sal comum; e da outra aquele precioso principio, exclusivamente a qualquer outro, vital e comburente de que já fallamos, e que faz com pouca differença uma quarta parte do ar atmosferico que respiramos. Estes dous principios combinados, e fundidos em a competente dose de calorico para os reduzir ao estado de um fluido elastico, constituem o dito-gaz, cuja denominação se deriva, segundo as Leis rigorosas da nomenclatura chimica actual, dos mesmos tres principios, calórico, ácido muriático, e oxygenio (ar vital). Tal he a sua composição” E de imediato observa, revelando o pormenor e o espírito crítico com que se mantinha a par das últimas descobertas: "as novas descobertas de Davi posteriores à epocha dos nossos trabalhos tem obrigado este Cel. Chimico e alguns outros a considerar o gaz muriatico oxigenado como hum corpo simples. Eu reservo para outro Escripto o exame d'esta theoria, que me não parece infirmar a que fica indicada sobre a composição d'este gaz" (SOBRAL 1813, pp.109-110).

Com o mesmo espírito crítico, se insurge contra aqueles que recorriam ainda, no ataque às epidemias do tipo daquela que grassava em Coimbra e outras partes do País, às populares fumigações baseadas no queimar de plantas balsâmicas e/ou resinosas:

"Todos os que persistem ainda hoje em inculcar fogueiras, seja de plantas aromáticas, balsamicas, resinosas, ou inodoras quando se trata de contagio e epidemias, dão huma prova demonstrativa de que ignoram de huma parte a verdadeira theoria da combustao; e que desconhecem de outra o verdadeiro alimento da sua vida; aquelle pabulum vitae de que nos alimentamos em todos os instantes da nossa existencia; e que por isso nos deve merecer mais atenção ainda que os outros alimentos que só tomamos a longos intervalos. Em huma massa qualquer d'ar que respiramos um unico principio nos he util e indispensavelmente necessario; todos os outros nos são ou indiferentes quanto à respiração, ou nocivos; e nos vem a ser mortaes, se os respiramos muito tempo, ou em grandes quantidades: he logo huma legitima consequencia d'estes principios hoje bem provados, que todos aquelles meios que roubarem ao ar, que respiramos, o único principio vital que n’elle existe, o tornam por isso mesmo deletério, mephitico, e 
irrespirável; e que diremos nós, quando os mesmos meios, ao mesmo tempo que roubam ao ar a sua parte respirável e vital, lhe dão em troca productos eminentemente deletérios? Tal he pois rigorosamente a combustao, quaesquer que sejam os corpos que se queimam, á differença só de mais ou menos. Toda a combustão he sustentada pelo mesmo principio vital do ar que respiramos, bem como a respiração; à excepção de que este principio terá o nome de comburente... Ora todos os corpos combustiveis, à excepção de poucos, fornecem, quando ardem, abundancia de productos deletérios e mephíticos de huma parte; e depauperam da outra o ar que respiramos do seu principio comburente (o mesmo que vital). Proscrevamos logo os fogos como meios contra-indicados sempre que se tratar de conservar a salubridade do ar, ou de restituir-lha” (SOBRAL 1813, pp. 122-123).

\section{Rodrigues Sobral, o "Lavoisier Português"}

Em carta dirigida a José Feliciano de Castilho ainda a propósito das novas aplicações do gaz muriático oxigenado, Rodrigues Sobral referindo-se à evolução da química flogística para a química pneumática, procura mostrar que uma e outra mais não são que diferentes modos de entender a natureza quando sujeita a idêntico processo inquisitivo, concluindo peremptoriamente: "O grande Lavoisier fixa de uma vez as opiniōes" (SOBRAL, 1814 A, p.103).

Esta não é a única vez que ele se refere a Lavoisier como o grande Lavoisier. Nas suas Reflexoes Geraes sobre as difficuldades de uma boa Analyse volta a fazê-lo e é novamente apodíctica a conclusão a tirar das suas afirmações:

“... Contudo as profundas vistas e reflexões do grande Lavoisier fizeram desaparecer todo o prestigio d'aquella doutrina, e mostraram que o Flogisto, principio mercurial, salino, térreo, como elementos dos metaes eram outros tantos entes imaginários; e as analyses que pareciam demonstrallos, illusórias, não sendo pela maior parte mais que syntheses” (Sobral, 1814 C, p. 255).

Até à jubilação de Domingos Vandelli, Lente proprietário da cadeira de Chimica, em 1791, a química era ensinada, na Universidade de Coimbra, segundo o Manual de J. A. Scopoli (SCOPOLI, 1777).

Usar um manual estrangeiro na leccionação de qualquer das disciplinas ministradas na Universidade reformada pelo Marquês de Pombal estava contra a vontade manifesta de sua Majestade, o Rei ou a Rainha. Em carta régia de 26 de Setembro de 1786, sua Majestade, a Rainha, mostrava-se muito apreensiva ao verificar

"com desprazer, que as repetidas ordenz que tem manifestado á Universidade, quanto à eficácia com que mandou que se compuzessem nela os compêndios para as lisoenz proprias de cada uma das Faculdades, nom tem produzido o efeito que era de esperar que produzissem e tendo em vista, que no espaço de quatorze anos com a demirassam das Universidadez estrangeiraz, nom tinha a de Coimbra produzido á luz escrito algum que fasa ver os progresos dela e esteja se servindo de livroz adaptadoz quando os podia ter proprioz". Na mesma carta, resolutiva e definitivamente mandava que em cada uma das Congregaçóes se tratasse sem perda de tempo da composição do seu compêndio próprio para servir ao uso do ensino público das suas aulas, deputando para isso uma ou mais pessoas escolhidas de entre os lentes catedráticos ou dos 
opositores mais dignos. E determinava que os que fossem deputados para tal tarefa houvessem logo de dar princípio à composição, sem lhes ser admitida escusa alguma (ACFF, 1978, p.63).

Em Congregação da Faculdade de Filosofia, realizada em Dezembro desse ano, Domingos Vandelli foi encarregado de elaborar os Prolegómenos para o sistema de Lineu, e o Compêndio de Quimica. Ainda que repetidamente instado pela Faculdade para o fazer, Domingos Vandelli nunca cumpriu a incumbência que lhe fora cometida, relativamente ao Compêndio de Química. Ao suceder-lhe como Director do Laboratório e Lente proprietário da cadeira de Química, Thomé Rodrigues Sobral foi incumbido, logo em Julho de 1791, de redigir ele próprio o desejado compêndio. Entretanto, as aulas de química continuavam a ser dadas usando como manual os Fundamenta Chemiae de Scopoli.

Nessa mesma Congregação da Faculdade de Filosofia foi decidido "transplantar-se na lingua nacional o artigo Affinité da Encyclopédie Méthodique da autoria do barão de Morveau". Segundo a proposta do director da Faculdade, o doutor Antonio Soares Barbosa, deveria encarregar-se dessa tradução o opositor doutor Luiz Antonio de S. Payo. Dela discordou, todavia, o Reitor que determinou que tal tradução competia ao demonstrador da cadeira de química, o Doutor Vicente Coelho de Seabra, para cujo fim foi eleito (ACFF, 1978, p. 119).

$\mathrm{Na}$ Congregação de 25 de Abril do ano seguinte, Thomé Rodrigues Sobral apresentou a primeira parte do plano do almejado compêndio de química, e em Julho, a parte restante.

Entretanto, em 1793, aparece publicado pela Real Imprensa da Universidade, o Tractado das Affinidades Chimicas, artigo que no Dicionario de Chimica, fazendo parte da Encyclopedia por ordem de matérias, deu Mr. De Morveau, traduzido e prefaciado por Rodrigues Sobral. Não se sabe porquê, nem como, a tradução para cujo fim tinha sido eleito Vicente de Seabra em desfavor de Luiz Antonio de S. Payo, acabaria por ser feita por Rodrigues Sobral. No prefácio de apresentação, diz Sobral:

“... Sendo sem dúvida o artigo cuja versão ofereço aos meus ouvintes, o que temos de mais completo nesta matéria, nem por isso deixa de ser susceptível de algumas reflexões, filhas dos conhecimentos posteriormente adquiridos, que pouco a pouco vão aproximando este objecto ao último ponto da sua perfeição. Eu me reservo porém propor estas reflexôes em o meu compendio de chimica, em o qual me proponho expor de um modo elementar todas as minhas ideias, ou, para o dizer melhor, o resultado dos imensos trabalhos dos melhores chimicos, o que constitui o estado actual dos conhecimentos chimicos, e uma das mais brilhantes Epocas desta ciência; contentando-me entretanto de enunciar em minhas Prelecções aquelas observações que julgar indispensavelmente necessárias aos principiantes, a quem somente dirijo este insignificante trabalho" (MORVEAU 1793, p.V).

A tradução em causa poderá explicar que entre a apresentação em Congregação da Faculdade do plano do compêndio de Química e a apresentação do compêndio propriamente dito medeiem mais de dois anos. $\mathrm{Na}$ verdade, este só acabaria por ser apresentado na Congregação de 31 de Julho de 1794, tendo sido então nomeado seu censor o doutor Manuel Jose Barjona. Na Congregação de 22 de Abril de 1795, foi o mesmo aprovado até ao parágrafo 243. Possíveis dificuldades surgidas com os 
parágrafos subsequentes (de cujo teor nada sabemos) terão sido a possível causa de se chegar a meados de 1798 e o compêndio não estar ainda definitivamente pronto para ser publicado, tendo, então, o professor Rodrigues Sobral sido "dispensado das aulas no ano lectivo próximo futuro de 1798 para 1799 , ficando somente obrigado à aula no primeiro dia lectivo de cada semana" para mais rapidamente poder satisfazer à tarefa de que estava incumbido (ACFF, 1978, pp. 242-244).

Entretanto, na Congregação de 30 de Julho de 1798 foi discutido "se se devia ou não continuar a ensinar chimica por outro compendio que não fosse Scopoli, enquanto o proprietário da cadeira de chimica não acabasse o compendio de que estava incumbido". Procedendo-se a votos, se determinou, que interinamente se ensinasse química pelos Elementa Chemiae de Jacquin. Como este compêndio era ainda raro entre nós e não haveria tempo de se mandar vir em abundância, dividiram-se os membros presentes na Congregação sobre o que fazer, verificando-se um empate de votos entre continuar-se a usar o manual de Scopoli e adoptar um manual da autoria de Xaptal (CHAPTAL 1790). Perante o empate verificado na votação, o Ex.mo senhor Principal Castro, reformador-reitor, que presidia à Congregação, encarregou o Secretário, o doutor Vicente Seabra, de dirigir um ofício ao director da Faculdade, doutor Antonio Soares Barbosa, que não estivera presente na reunião, para dar o seu parecer e voto por escrito.

O Director deu a sua resposta na forma seguinte:

"Em observancia da ordem de Sua Excelência pella qual se me manda responder como meu parecer sobre o que se propoz em Congregação, e ficou empatado pellos vogaes, respondo o seguinte: sempre foi bem constante a Sua Excelencia e a toda a Congregação o meu sentimento a respeito do Scopoli; e por isso sempre o regeitei, e regeito como incapaz para o ensino público, como indigno de apparecer nas prezentes luzes da chimica, e alem disso como vergonhozo para os que o apadrinham, e infamatorio para a Faculdade. Fui de parecer, que se ensinasse por Lavoisier pello crer mais conforme à chimica geral filosofica, a qual tão somente manda ensinar o Estatuto de Filosofia prohibindo na mesma filosofia o ensino da chimica médica, e farmacêutica. Porem já que a Faculdade não foi para ahi, voto só a fim de desterrar o Scopoli, que se ensine interinamente pello Xaptal, enquanto não houver cópia suficiente de Jacquin, ou de outro melhor, que for mais apropriado aos fins da Faculdade segundo manda o Estatuto" (ACFF, 1978, p. 23).

Em consequência deste voto ficou adoptado interinamente o compêndio de Jacquin enquanto o proprietário da cadeira não acabasse o seu próprio manual; e à falta de exemplares de Jacquin deveria usar-se o compêndio de Xaptal até que esses exemplares fossem conseguidos ${ }^{1}$.

Considerando a doutrina química exposta por Morveau no Tractado das Affinidades Chimicas o que havia de mais completo na matéria desta ciência, compendiando as teorias desenvolvidas por Lavoisier e seus colaboradores, no Compêndio cuja redacção tinha em mãos, Rodrigues Sobral adoptava-as e seguia-as de perto. Era a doutrina de Lavoisier vertida em português e para uso dos portugueses. Por razóes que continuam

${ }^{1}$ O Manual de Jacquin seria, entretanto, publicado pela Universidade, mas só em 1807 - Joseph Francisci A. JACQUIN 1807, Elementa Chemiae Universe et Medicae - Praelectionibus suis accomodata, Conimbricae, Typis Academis. 
desconhecidas, esse compêndio não chegou a ser publicado ${ }^{2}$. Sabemos que foi queimado com o resto do recheio da casa que Rodrigues Sobral possuía em Coimbra, na Quinta da Cheira, à Arregaça, quando incendiada pelas tropas francesas comandadas pelo marechal A. Massena, em retaliação do apoio que ele prestara, anos antes, ao combate das tropas comandadas por General Junot. Nesse incêndio não escapou um só volume da rica Biblioteca que o Professor possuía. "Nele foram irreparavelmente destruídos todos os preciosos manuscritos que possuía, e especialmente o seu compêndio de química, fruto de aturados estudos e meditaçôes" (Castilho, 1814, p. 286; Sobral, 1816, p. 305). No testemunho que sobre o assunto nos deixou Link na sequência dos contactos que manteve, em Coimbra, ao longo dos anos de 1797-1799, não deixa margens para dúvidas sobre a natureza do Compêndio em causa:

"Don Thome Rodrigues Sobral, professeur de Chimie, est un homme trés-habile. II connait les procédés actuel des Français dans cette science; il enseigne la chimie d'aprés les nouveaux principes antiphlogistiques; il a même traduit leur nomenclature en portugais, et s'occupe maintenant a publier un manuel de chimie, qui manque en Portugal. Je ne doute nullement de son succés" (LINK 1808, Tom. I, pp. 300-301).

\section{Rodrigues Sobral, o "Chaptal Português"}

Este epíteto atribuído a Rodrigues Sobral foi salientado pelo Professor A. Simões de Carvalho na sua Memória da Faculdade de Filosofia de 1872, referindo que se trata da justiça que lhe fizeram os sábios escritores Link e Balbi, por comparação com o trabalho desenvolvido por Jean Antoine Chaptal (1756-1832), o médico francês que se notabilizou na química industrial e cujo Ensaio sobre o aperfeiçoamento das Artes Químicas em França, editado em 1800, é das mais importantes marcas no desenvolvimento da química aplicada. É o mesmo Chaptal cujo Manual havia sido referido na Congregação da Faculdade de Filosofia da Universidade de Coimbra, na sessão de 30 de Junho de 1798, em que se considerara qual o compêndio a adoptar para o ensino da química, em substituição do Manual de Scopoli que estava a ser usado.

Formado em Medicina pela Universidade de Montpellier, J. A. Chaptal celebrizou-se, em particular, pelos seus trabalhos de aplicação da química ao serviço da indústria, com especial incidência na regulação da indústria das águas minerais, a preparação e organização de exposições de produtos industriais, o estudo da vinicultura e o desenvolvimento das estradas e canais. Votou especial atenção à melhoria da produção do ácido sulfúrico, do salitre para produção de pólvora, a preparação do açúcar de beterraba, etc. De 1790 a 1823 publicou onze volumes dando conta dos seus muitos trabalhos sobre estes assuntos.

\footnotetext{
${ }^{2}$ Num Livro de Inventários do Dispensatório Pharmacêutico da Universidade de Coimbra, aberto a 13 de Novembro de 1798 , no art. ${ }^{\circ}$. $^{\circ}$ do Tit. $1 .^{\circ}$., a fl19V, relacionando os Livros existentes, refere-se a existência duma Chymica de Sobral em $8^{\circ}$. Onde parará o exemplar em questão? Não deveria tratar-se de exemplar único no País posto que esta referência é a de uma obra impressa.
} 
Esta simples referência aos múltiplos trabalhos de Chaptal como químico torna óbvio e natural que se possa referir a actividade química de Rodrigues Sobral comparando-a com a dele.

Cumpridas as tarefas químicas de ajuda às tropas portuguesas durante as invasões dos franceses, e no empenho que pôs no atalhar os progressos do contágio da epidemia que grassou na cidade de Coimbra e no País na sequência das mesmas, deparamo-nos com um Thomé Rodrigues Sobral totalmente empenhado em tornar o Laboratório Chimico "de grande utilidade para a Nação; de interesse para a Universidade; de crédito e consideração para as outras Naçôes". Ao serviço do ensino público, nele se deviam explicar as teorias ou verdades fundamentais da ciência química, tendo em conta a extensão das suas matérias e o grande número das suas descobertas que, citamos, "há pouco mais de trinta anos a esta parte, é possível confirmar com experiências em pequeno, compatíveis com um edifício assaz limitado, uma vez que não exigem nem um local extenso, nem uma grande quantidade de fornalhas, nem outros grandes aparelhos" (SOBRAL B, pp.292-293).

Quanto à química aplicada, estava Rodrigues Sobral empenhado em que o Laboratório pudesse servir esta nos seus diversos, interessantes e múltiplos usos, já na Medicina, já nas diferentes Artes, a maior parte das quais devem à ciência química ou a sua primeira existência e criação, ou a sua perfeição e melhoramento. Para tanto precisava o Laboratório de "um muito maior número de vazos, instrumentos e aparelhos e toda a sorte de utensílios, bem como uma ou mais casas destinadas à boa arrecadação e conservação dos differentes productos" (Sobral, 1816 B, pp. 294-295). Claramente, para Rodrigues Sobral, o Laboratório da nossa Universidade havia sido:

"destinado, desde a sua primeira criação, não só para a pública instrucção da Mocidade Portuguesa, que se dedicasse ao estudo das Sciencias Naturaes, vindo assim a ter um fim commum com os outros Estabelecimentos philosophicos desde a feliz plantação das Sciencias Naturaes na Universidade, mas também para aquelles trabalhos em grande, que se-julgassem ou mais importantes, ou mais compatíveis com a sua capacidade, com o seu local, e com outras muitas circunstâncias que devem attender-se na fundação de um Laboratorio destinado a trabalhos em grande. Todas as sábias disposiçōes e providências que se-achão nos Estatutos da Universidade relativas a este Estabelecimento, todas mostram as grandes utilidades que se-tiveram em vista na sua fundação: a extensão, capacidade, e magnificência do edifício; a criação de um Operario Mestre do Laboratorio, com seu ordenado avultado (n’aquelle tempo); a cláusula mesma expressa nos Estatutos, de não haver férias n'esta officina; cláusula que se não põe a respeito de algum dos outros Estabelecimentos da Faculdade; acabam de confirmá-lo. (...) Desejando pois eu cooperar, quanto estiver em mim, com os desejos que $S$. Ex.a me-tem manifestado, e com a firme resolução, na qual o mesmo Senhor parece ter entrado, de que vão sem perda de tempo a estabelecer-se no Laboratório os trabalhos em grande a que fora destinado desde a sua fundação, ou pelo menos aquelles que, attendidas todas as condiçōes, n'elle se-poderem hoje praticar com utilidade; vou indicar no seguinte catalogo alguns artigos sobre os quaes muito principalmente me-parece que o Laboratório poderá empregar-se vantajosamente, como he de esperar que seja, fornecido de todos aquelles meios que se-julgarem necessarios. Estes artigos podem considerar-se fornando duas grandes classes: na pimeira se-comprehendem todas aquellas preparaçôes Chimicas que são de um uso frequente na Medicina; das quaes umas pertencem à Chimica Mineral, outras à Chimica Vegetal e outras à Chimica Animal, e todas ellas à Chimica Pharmaceutica." 
Para o efeito, exigiam-se "não só conhecimentos químicos" como também "grande zelo do bem público, uma delicadeza e boa fé que por via de regra se-encontrão poucas vezes em todos os indivíduos que ou dirigem ou executam trabalhos em grande em matéria a objectos commerciaes" (SOBRAL 1816 B, pp. 309-310).

Deixando bem claro quanto o zelo pelo bem-público era uma das grandes linhas orientadoras de todo o seu trabalho químico, ao mencionar os trabalhos em grande que no Laboratório Químico era possível realizar, Rodrigues Sobral, referindo-se ao tartrato addulo de potassa, escreve:

"Este sal he um dos exemplos que provam até à evidência a nossa negligencia e indifferença a respeito dos nossos interesses Nacionaes. Quasi todo o sarro do Alto Douro he vendido ao Estrangeiro, a quem o recompramos purificado; pagando-lhe talvez por um arratel, o que ele nos paga por uma arroba. Já tirei de uma arroba de bom sarro branco 11, 12, e 15 arrateis: o cálculo he facil do que nos perdemos, e lucra o Estrangeiro" (SOBRAL 1816 B, p. 310).

E a propósito do nitrato de potassa, depois da referência aos trabalhos de preparação de pólvora no Laboratório Químico durante as invasões francesas, conclui: "he também por esta razão que eu recordo hoje a S. Ex." (o reitor-reformador, D. Francisco de Lemos) quaes eram, já há vinte annos, as vistas do Ministro e Secretario d'Estado o Ex.mo D. Rodrigo, sobre estabelecer-se no Laboratorio de Coimbra uma boa nitreira à imitação da que o mesmo Ministro havia feito construir em Lisboa à borda do Tejo"; na falta dela "fui reduzido a fazer apenas um pequeno ensaio de nitreira (em local bem pouco apropriado)"; nela "se algumas cestas de terra mal nitrificada por defeito do local e das condições favoráveis, me-tem dado arrateis, maiores quantidades em outras circunstancias nos-teriam dado arrobas. A natureza sendo a mesma obrando em pequeno ou em grande, nos daria agora grandes quantidades de salitre se nós lhe tivéssemos presentado grandes massas de terra sobre que exercesse a sua acção nitrificante; e S. Ex.a teria hoje a satisfação de ver o fructo de uma boa nitreira" (SOBRAL 1816 B, pp. 305-306).

A propósito do oxalato acídulo de potassa, o sal essencial d'azedas, escreve:

"Ainda que este sal não constitua em si mesmo um artigo muito importante; com tudo os Allemaes o-têm ha muito tempo tornado do interesse da sua Nação fazendo d'elle um comércio exclusive: e Bayen o-julgou igualmente interessante para a França aonde procurou introduzir a sua preparação. He bem digna de citar-se a reflexão que elle faz por esta occasião: e eu referirei fielmente a sua passagem, que me parece vir muito a propósito a nosso respeito, e confirmar o meu modo de pensar em circunstâncias análogas que fizeram objecto de outro meu Escripto (Noticias de differentes minas, etc., etc. (Jornal de C. Num. XLVI. Parte I, pag. 221). L'importation de ce sel en France, dizia Mr. Bayen, n'est pour l'etat une affaire de grande consequence, mais à moins d'une necessité absolue, peut-on laisser sortir du royaume la plus petite somme d'argent? Non sans doute, et nous croyons que l'importation du sel d'accille ne coutat elle a la France que dix mille livres par an, doit être, non pas prohibée, mais redue nulle par l'etablissement de quelques usines oú on le fabriquerait. (Annales de Chemie, Tome XIV, p. 4)" (SOBRAL 1816 B, pp. 306-307).

E referindo-se às quinas do Brasil, em cuja análise estava a trabalhar, "em observância das Reaes Ordens" que a este respeito haviam sido dirigidas ao reitor da 
Universidade, faz sua a exclamação de Lineu, numa carta dirigida a Vandelli: "Bone Deus, si Lusitani noscent sua Bona Natura, quam infelices essent plerique alii!" - "Santo Deus, se os portugueses conhecessem as riquezas que a natureza lhes deu, como seriam infelizes tantos outros!" (LINEU 1765, citado in SOBRAL 1816 A, p. 237).

A mesma tecla é batida constantemente no seu Tratado sobre as dificuldades de uma boa análise:

«He bem de lamentar que sendo Portugal tão rico e favorecido da Providência em aguas mineraes especialmente sulphureas e Marciaes, eu me-veja obrigado a ir buscar exemplos a outras Naçôes! Estudamos com interesse quantas aguas mineraes analysadas tem a França, a Inglaterra, a Suécia (...) e ignoramos quasi absolutamente ou desprezamos os thesouros que n'este género temos d'entro em casa. Intus talpae; foris lynces” (,,,) . não conheço senão duas analyses das nossas águas mineraes sulphureas (...) ambas relativas às Caldas da Rainha. (...) A primeira que he do Dr. Jose Martins da Cunha Pessoa tem o inseparável merecimento de offerecer como primeiro fructo da Sciencia Philosofica plantada na Universidade. (...) A segunda analyse he do Cel. Whitering, Philosopho Inglez (...) mandada fazer, ao que parece, pelo Ministerio Inglez (...), uma tácita reprehensão à nossa indifferença“" (SOBRAL 1814 C, pp. 258-259).

Mas é, sobretudo, na sua Notícia de differentes Minas Metallicas e Salinas que mais transparece o profundo zelo pelo bem público que informava todo o seu trabalho científico. Citamos:

“O nosso Paiz não he um dos menos favorecidos pela Natureza (...) mas apezar das riquezas naturaes que gratuitameme nos offerece ainda hoje preferimos enriquecer os outros com o numerario que lhes-damos pelos metaes de que tanto carecemos. (...) Se se-houvesse applicado ate agora mais industria e cuidado no melhoramento do ferro que se-extrahe nas nossas ferrarias que sommas incalculáveis não teriam ficado em Portugal!? Um exemplo bem recente e que me-he bem desagradável em um sentido, confirmará o que fica dito, e servirá de monumento que atteste aos séculos futuros ou a nossa pobreza, ou a nossa negligência n'este artigo até à épocha presente. Fallo da somma de muitos mil cruzados que ou já enviámos, ou temos de enviar para a Suécia, pelo ferro com que deve formar-se a grande balaustrada que deve cercar o nosso Jardim Botânico: obra soberba e digna do grande Prelado que a-manda executar. Quem pensara depois d'este facto que a oito léguas de Coimbra uma rica mina de ferro está actualmente em actividade?” (SOBRAL 1816 A, p. 222).

Os objectivos que punha na análise de diversas minas metálicas que lhe chegavam de variadas partes do País e que ele próprio ia, muitas vezes, observar in loco deixou-os ele bem definidos:

“1. ${ }^{\circ}$ - assignar as localidades d'estas riquezas territoriaes, para que julgando-se do interesse público o tornal-as uteis ao Estado, se-possa sem novos trabalhos e indagações saber com segurança a sua existência. Que importaria crer-se geralmente que temos minas, e ignorar-se onde existem; ou sabendo-se onde existem, despresal-as? Isto seria o mesmo que ficarmos pobres no meio das riquezas; escravos e dependentes, cercados de meios de independência. $2 .^{\circ}$ - excitar, se podér, por este modo ao descobrimento dos differentes Mineraes aquellas pessoas das Provincias que ou por alguns conhecimentos mineralogicos que possuam; ou ainda que sem 
elles, por motivo de recreação nos espaços, que lhes deixarem livres suas obrigações quaesquer, se-acharem mais em circunstâncias de o-poder fazer e de descobrir sem grandes sacrifícios, nem apparato de viagens, os differentes Mineraes que podem existir nos districtos de suas habitações. A publicidade que eu me-proponho dar por meio do J. de C. às suas descubertas, deve ser já um estímulo que os-excite, e ate um prémio que os-compense do pequeno sacrifício que tiverem feito de algumas horas de descanço. A publicação honrosa dos seus nomes os-fará olhar como Cidadãos beneméritos da Nação como tendo posto à sua disposição algum novo artigo da sua riqueza territorial. 0 homem he naturalmente ambicioso de louvor: pendemus ex laude: et hanc nostri laboris dicimus summam: todo o louvor, que se-procura e ganha por serviços à Patria, nada tem de sórdido; e a ambição que o solicita nada tem de viciosa: vício he neste caso não ser ambicioso" (SOBRAL $1816 \mathrm{~A}$, pp. 223-224).

Referindo-se ainda ao jazido de sulfureto de ferro que havia sido descoberto junto à Vila de Miranda do Corvo, a mina de ferro a que aludira quando lamentou a importação do ferro usado para o gradeamento do Jardim Botânico, escreve:

"Porque razão não faremos nós uma tão barata preparação depois de nos-aproveitarmos dos outros productos úteis, que esta e outras semelhantes Minas, de que Portugal abunda, nos-offerecem? Eu não posso descobrir outra alguma razão que nos-desculpe, a não ser a de havermos sido como condemnados pela Providência a uma escravidão perpétua; ainda n'aquelles artigos mais capazes de nos-tornarem superiores, logo que conheçamos melhor do que até aqui, os bens que possuimos, e cesse a nossa indifferença e negligencia em approveital-os (...). Os objectos de pública utilidade devem em todo o tempo dar-nos olhos de todo o bom Cidadão: elles devem em todo o tempo, e logo que se-conheçam, ir tocar o coração de um Soberano digno do Nome de Pai Commum; e excitar o zelo d'aquelles Ministros, por cuja conta corre o vigiar sobre as necessidades e os interesses do Estado, que o mesmo Soberano tem commettido as suas luzes; e promover por todos os modos possíveis os interesses da Nação. Mas infelizmente a reunião d'estas circunstâncias favoráveis raras vezes tem lugar: o Soberano, que por si mesmo não pode vigiar sobre todas as necessidades dos seus Vassalos, fica muitas vezes, apesar das suas melhores intenções e paternaes sentimentos, ignorando meios bem fáceis de as-fazer cessar, por falta de quem lh'as communique. 0 Ministro aliás Sábio, activo, e zeloso, ignora às vezes uma fonte de riqueza nacional, e consente, sem querer, que se-enriqueçam os Estados vizinhos com o numerário que serviria a enriquecer o seu. 0 Cidadão vê-se, por mil causas conspirantes, na impossibilidade de fazer chegar, ou à presença do Soberano, ou ao conhecimento dos seus Ministros muitos objectos d'utilidade para elle mesmo, e para a sua Nação; e o resultado fatal do concurso a estas causas, he a perpétua dependência da Nação das suas vizinhas mais industriosas, e mais vigilantes sobre os seus interesses, mas não mais ricas (...). Nem se-diga que objectos de tão pouca monta, como este que ultimamente me occupa, pouca, ou nenhuma influencia podem ter na prosperidade geral de uma Nação, e na sua independência de qualquer das outras. Eu não admitto objectos de pouca monta, se não em relação a outros de primeira ordem, quando se trata dos interesses de uma Nação. Uma grande somma resulta necessariamente da reunião de parcellas bem pequenas: ella poderá sim formar-se mais rapidamente com parcellas maiores, mas será sempre da sua essência ser producto das mais pequenas. Se um pequeno artigo qualquer commercial preparado no Paiz pode impedir a sahida p. ex. de um milhão para o Estrangeiro, muitos artigos semelhantes pouparão a sahida de muitos milhôes, que servirão a muitas outras applicações úteis à Nação" (SOBRAL 1816 A, p.224; p. 238). 


\section{E conclui peremptório:}

"Se he útil que no Reino haja Minas de todo o género, também o-deve ser que se-conheção e se-saiba onde existem: e ainda mais útil o-deve ser que ellas se-aproveitem; alias cui bono?” (SOBRAL 1816 A, p.240).

\section{CONCLUSÃo}

Terminaremos as nossas considerações sobre a análise química na Universidade de Coimbra ao tempo de Rodrigues Sobral, referindo aqui, ainda que muito resumidamente, os três escritos de sua autoria que redigiu a propósito da análise de quinas recebidas do Brasil, com empenho especial da Casa Real, para que fosse cuidadosamente investigado do ponto de vista químico e médico, o seu princípio febrífugo.

Ao apresentar os resultados do ensaio químico que fez da quina conhecida no Brasil por Mil-Homens (Sobral, 1814 B), Rodrigues Sobral fez publicar um conjunto de reflexões gerais sobre as dificuldades de uma boa análise, principalmente vegetal (SOBRAL 1814 C) e, posteriormente, uma longa memória sobre o Princípio Febrífugo das Quinas (SOBRAL 1819). Estes três escritos juntamente com os resultados da análise química duma mina metálica por ele realizada e apresentados a pp. 91-96 no mesmo volume do Jornal de Coimbra em que apresenta os resultados da análise química da quina Mil-Homens, constituem um verdadeiro e longo tratado de Análise Química, do qual nos permitimos ressaltar:

\footnotetext{
"Uma análise química qualquer, e muito especialmente uma analyse vegetal ou animal, he o tabalho mais difícil de toda a Chimica (...), a pedra de toque que distingue o Chimico profundo d'aquelle que o não he. (...) A Analyse chimica tem sempre este único problema que resolver: quantos e quaes são os princípios ou elementos, sejam próximos, sejam remotos, que compõem o corpo que se-analysa; quaes são as proporções respectivas destes princípios, seja dos immediatos e ainda compostos; seja dos elementares, e sobre os quaes os meios de analyse actuaes já nada podem”.
}

Dos três tipos de análise química, a mineral, a vegetal e a animal, "a analyse dos mineraes, (a analyse dos metaes e suas minas) he necessariamente mais simples e menos complicada pela mesma simplicidade da sua composição, pela natureza dos seus princípios ou mais fixos, ou menos destructiveis e alteráveis (...) constando pela maior parte de três princípios, a saber, um acido, uma base, e mais ou menos agua" (SOBRAL 1814 C, pp. 252-254). Também a análise química das águas "não he tão complicada como pareceria à primeira vista" pois o seu contento são "alguns saes, terras, um pequeno número de metaes, ou algumas combinações hepáticas, servindo-lhes a água ou de dissolvente ou de vehiculo", sendo, todavia, de concordar com o que sobre ela diz Henry " $L$ 'analyse complete et exacte dês eaux minerales et dês corps mineraux en general, est un dês sujets les plus difficiles de la chimie pratique, et elle exige une connaissance très étendue dês proprietés et dun mode d'action d'une classe très nombreuse de corps". "Mas, apesar de quanto a chimica dos vegetaes tem ganhado em preciosas descobertas, conhecimentos úteis e applicações felizes a todas as Artes 
chimicas que têm por base as substancias vegetaes, à Medicina, etc”... impóe-se reconhecer "quanto he difficil uma boa e exacta anályse vegetal; quanto uma tal analyse he rara; quanto se deve desconfiar da maior parte das que existem"; "as difficuldades que offerece uma analyse vegetal qualquer, se augmentam além das que são communs a toda a anályse, $1 .^{\circ}$ pela ordem de composição das substancias vegetaes, comparadas com a mineraes; $2 .^{\circ}$ pela natureza volátil da maior parte dos seus principios elementares; e ainda mesmo por alguns immediatos e compostos; $3 .^{\circ}$ pela natureza e carácter das combinações dos mesmos elementos de serem facilmente alteraveis pelo fogo, pelo ar, e por todos os agentes, com poucas excepçōes; $4 .{ }^{\circ}$ pela complicação das suas attracções, pela facilidade com que a ordem d'estas attracções he alterada e mudada, etc., etc., etc..." Os elementos que neles predominam "como são o hydrogenio, o carbonio, o oxygenio, e o azote, são de uma natureza tão subtil; são tão fugazes (se exceptuarmos o carbonio) que estando livres das combinações que os retêm, às primeiras impressões de uma temperatura um pouco augmentada desapparecem fundidos no calórico em forma de fluidos elásticos”. Daí a conclusão: uma análise química em geral, e muito particularmente uma análise vegetal, "para merecer alguma confiança deve necessariamente ser longa, extensa e vagarosa, que toda a precipitação nas experiências, toda a impaciência em esperar pelos seus resultados devem ser oppostas e fataes ao fim da mesma analyse. Com efeito, quem não vê que huma analyse he um como resumo pratico de toda a chimica; hum complexo de todas as suas operações? Além das operações preparatórias, huma analyse comprehende dissoluçōes, precipitaçôes, infusões a frio, e a calor, decocções mais ou menos longas, filtraçōes mais ou menos difficeis e morosas; destillações, evaporaçôes ou espontâneas ao ar livre, ou promovidas e aceleradas pela acção do fogo, cristalizações, combustóes, carbonizações, incinerações, etc., etc. etc. (...) Nós lemos muitas vezes em poucas páginas, o que se-achou por experiências de muitos mezes, e talvez annos" (SOBRAL 1814 C, pp.257-265).

Os resultados da análise química que fez da quina Mil-Homens (SOBRAL 1814 B) e, na sequência dos mesmos, as reflexôes que apresentou sobre o princípio febrífugo das quinas em geral (SOBRAL) são o exemplo prático e acabado do quanto sobre o assunto antes escrevera e fizera.

\section{REFERÊNCIAS}

ACFF - Actas das Congregaçōes da Faculdade de Filosofia (1772-1820). Coimbra: Edição da Universidade de Coimbra, 1978.

AMORIM-COSTA, António M. - Primórdios da Ciência Química em Portugal. Lisboa: Instituto de Cultura e Língua Portuguesa, 1984. No 92 (Biblioteca Breve)

CARVALHO, Joaquim Augusto Simões de - Memoria da Faculdade de Filosofia. Coimbra: Imprensa da Universidade, 1872.

CASTILHO, José Feliciano de - Reflexões sobre um escrito de Bernardino António Gomes publicado no Investigador Portuguez em Inglaterra. Jornal de Coimbra. Coimbra: [s.n.]. VI, pt. 1 (1814), p. 277-287.

CHAPTAL, Jean-Antoine - Élémens de Chymie. Montpellier: Imprimerie de Jean-François Picot, 1790. 3 vol.

LINEU, Carl - [Carta] 1765 Fev. 12, Upsala [a] Domingos Vandelli [Manuscrito]. 1765. Carta VIII.

LINK, Heinrich Friedrich - Voyage en Portugal depuis 1797 jusqu'en 1799. Paris: Dentu Imprimeur-Libraire, 1808. 3 vol.

GUYTON DE MORVEAU, Louis-Bernard - Tractado das Affinidades Chimicas, artigo que no Dicionario de Chimica, fazendo parte da Encyclopedia por ordem de matérias, deu Mr. De Morveau. Coimbra: Real Imprensa da Universidade, 1793. 
NEVES, José Acúrcio das - Memorias sobre os meios de melhorar a Industria Portuguesa. Lisboa: [s.n], 1820.

SCOPOLI, Giovanni Antonio - Fundamenta Chemiae Praelectionibus Publicis Accomodata, Praga: Apud Wolfgangum Gerlb, 1777.

SOBRAL, Thomé Rodrigues - Diário das operações que se fizerão em Coimbra, a fim de se atalharem os progressos do Contágio, que n'esta Cidade se declarou em Agosto de 1809. Jornal de Coimbra. V, Pt I (1813) p. 103-138. O conteúdo deste trabalho é o dos relatos que haviam sido feitos por Thomé Rodrigues Sobral em colaboração com Jerónimo Joaquim de Figueiredo, em 1909, na Minerva Lusitana, nos n. ${ }^{\circ}$ s 143, 144, 146, $148,151,152$ e 153.

SOBRAL, Thomé Rodrigues - Carta do Dr. Thomé Rodrigues Sobral ao Dr. José Feliciano de Castilho em resposta a outras em que se tratava de uma nova applicação do Gaz Muriático Oxigenado. Jornal de Coimbra. VII, Pt I, (1814) p. 101-136.

SOBRAL, Thomé Rodrigues - Ensaio Chimico da Planta chamada no Brasil Mil Homens, Aristolochia Grandiflora segundo o Dr. Bernardino António Gomes. Jornal de Coimbra. VII, Pt I, (1814) p. 149-198.

SOBRAL, Thomé Rodrigues - Reflexões geraes sobre as difficuldades de uma boa Analyse principalmente vegetal, para servirem, de resposta a uma pergunta que se fez ao author. Jornal de Coimbra. VII, Pt. I (1814) p. 251-266.

SOBRAL, Thomé Rodrigues - Notícia de Differentes Minas Metálicas e Salinas. Jornal de Coimbra. IX, Pt. I (1816) p. 221-240.

SOBRAL, Thomé Rodrigues - Nota sobre os Trabalhos em grande que no Laboratório Chimico poderão praticar-se com mais utilidade do Publico e com maiores vantagens do mesmo Estabelecimento. Jornal de Coimbra. IX, Pt. I, pp. 293-312.

SOBRAL, Thomé Rodrigues - Methodo Prático de Purificar as Cartas e Papeis procedentes de Paizes contagiados ou suspeitos. Jornal de Coimbra. X, Pt I (1817) p. 101-130.

SOBRAL, Thomé Rodrigues - Memoria sobre o Princípio Febrífugo das Quinas. Jornal de Coimbra. XV, Pt I (1819) p.126-153. 